\title{
Botulinum toxin for conditions of the female pelvis: comment
}

\author{
F. Israfil-Bayli • C. Burton • M. Parsons • S. Bulchandani • \\ P. Toozs-Hobson
}

Received: 8 March 2013 / Accepted: 16 March 2013 / Published online: 14 May 2013

(C) The International Urogynecological Association 2013

\section{Dear Editor,}

We have read with interest the report by El-Khawand and colleagues on use of botulinum toxin for conditions of the female pelvis [1]. The authors describe with a systematic approach the mechanism of action of botulinum toxin and its use in different urogynaecological conditions and pelvic floor disorders. It was of particular interest for us to read about the use of botulinum toxin in high-tone pelvic floor dysfunction (pelvic floor muscles spasm), myalgia or vestibulodynia, as we have used it in selected patients for the same conditions in our unit.

There are several studies confirming that the muscle spasm could be relieved by the injection of botulinum toxin type A directly into myofascial trigger points [2], leading to a significant reduction in pelvic floor pain. The disadvantages of this treatment are the need for general anaesthesia and the temporary nature of the effect of botulinum toxin on the muscle, necessitating repeated injections.

The authors mention that the aetiology of the condition is uncertain and that diagnosis is made only by history and physical examination. There is some evidence in the literature that pelvic floor dysfunction, spasms and associated pelvic floor pain could be attributed to traumatic childbirth and be the result of pelvic floor muscle damage or denervation [3]. Usually, pelvic floor trauma comprises perineal and anal sphincter damage, but recently levator muscle damage

F. Israfil-Bayli $(\bowtie) \cdot$ C. Burton $\cdot$ M. Parsons $\cdot$ S. Bulchandani $\cdot$

P. Toozs-Hobson

Birmingham Women's Hospital NHS Foundation Trust,

Mindelsohn Way,

Edgbaston, Birmingham B15 2TG, UK

e-mail: fidan.israfilbayli@bwhct.nhs.uk

F. Israfil-Bayli

e-mail: drbayli@yahoo.co.uk
(LAM) has been included in this group [4]. It is well known that LAM trauma, and as a consequence chronic pelvic floor pain, is commonly seen in multiparous women with a history of forceps delivery. With regard to diagnosis, several clinical and imaging techniques are currently used in diagnosing levator muscle injury, such as ultrasound and MRI.

We would also like to share our experience of injecting botulinum toxin into myofascial trigger points in the outpatient setting, which makes this method more accessible and especially successful, as patients could directly comment on the painful trigger points, assuming that the procedure is tolerated well. It also reduces the risk by avoiding anaesthetic, and in these times of austerity, improving costeffectiveness.

To our knowledge this method has not been described before in the scientific literature in women with pelvic floor disorders.

Conflict of interest None.

\section{References}

1. El-Khawand D, Wehbe S, Whitmore K (2013) Botulinum toxin for conditions of the female pelvis. Int Urogynecol J. doi:10.1007/ s00192-012-2035-1

2. Abbott JA, Jarvis SK, Lyons SD, Thomson A, Vancaille TG (2006) Botulinum toxin type A for chronic pain and pelvic floor spasm in women: a randomized controlled trial. Obstet Gynecol 108(4):915-923

3. South MM, Stinnett SS, Sanders DB, Weidner AC (2009) Levator ani denervation and reinnervation 6 months after childbirth. Am J Obstet Gynecol 200:519.e1-519.e7

4. Schwertner-Tiepelmann N, Thakar R, Sultan AH, Tunn R (2012) Obstetric levator ani muscle injuries: current status. Ultrasound Obstet Gynecol 39:372-383. doi:10.1002/uog.11080 